\title{
EXPERIMENTAÇÃO DE UM PROJETO DE INICIAÇÃO CIENTÍFICA NA MODALIDADE A DISTÂNCIA SOBRE HABILIDADES MATEMÁTICAS PARA ENGENHEIROS
}

\author{
LONDRINA/PR MAIO/2018
}

\author{
Helenara Regina Sampaio Figueiredo - Unopar - helenara@kroton.com.br \\ Debora Cristiane Barbosa Kirnev - Unopar - deborabarbosa09@yahoo.com.br \\ Jenai Oliveira Cazetta - Unopar - cazetta.jenai@gmail.com \\ Patrícia Beneti de Oliveira - Unopar - patriciabeneti@gmail.com \\ Keila Tatiana Boni - Unopar - keila.boni@unopar.br \\ Diego Fogaça Carvalho - Unopar - diego.fogaca@kroton.com.br \\ Renata Karoline Fernandes - Unopar - renata.karoline@kroton.com.br
}

Tipo: Relato de Experiência Inovadora (EI)

Categoria: Conteúdos e Habilidades

Setor Educacional: EDUCAÇÃO SUPERIOR

\section{RESUMO}

Este relato de experiências tem como objetivo descrever o modo como está sendo desenvolvido o projeto de Iniciação Científica voltado a estudantes de Matemática de um curso ofertado na modalidade de Educação a Distância. O projeto de Iniciação Científica que compõe esse relato parte da inferência sobre habilidades matemáticas que os ingressantes de Engenharia apresentam. Para a realização da Iniciação Científica na Educação a Distância, os estudantes desenvolvem atividades em um Ambiente Virtual de Aprendizagem, bem como encontros com os professores participantes de forma síncrona e assíncrona.

Palavras-chave: Habilidades, Engenharia, iniciação científica.

\section{AGRADECIMENTOS}

\section{FUNADESP}




\section{Introdução}

Os cursos de formação superior devem propiciar aos estudantes de graduação oportunidades de aprendizagem por meio de experiências diversificadas ao longo de sua formação. Um Projeto de Iniciação Científica (PIC) é um meio de inserir o graduando em uma comunidade científica. Levando isso em consideração, desenvolvemos um projeto de iniciação científica extracurricular, com o objetivo de dar a oportunidade, aos estudantes do curso de Licenciatura em Matemática EaD, com abrangência nacional, de participar de atividades direcionadas, expandindo, assim, seus conhecimentos acadêmicos.

O projeto tem o objetivo de evidenciar competências e habilidades matemáticas manifestadas por estudantes ingressantes dos cursos de Engenharia. Nesse sentido, temos um caráter interdisciplinar, devido à dinâmica da pesquisa a ser desenvolvida, na qual o graduando de Matemática vai a campo, em seu polo, e convida outros alunos, ingressantes do curso de Engenharia, para participar da pesquisa. Uma vez que o futuro engenheiro aceita o convite, é proposta uma sequência de atividades a serem desenvolvidas, nas quais o graduando de Matemática atua como investigador de campo. Mediando esse processo, temos os professores colaboradores que orientam a pesquisa de campo dos estudantes de IC.

Neste artigo, evidenciamos as expectativas de estudantes enquanto pesquisadores de um projeto de iniciação científica em um curso de Licenciatura em Matemática, ofertado na modalidade EaD e suas possíveis contribuições no espaço de formação.

\section{Referencial teórico}

Para Zakon (1989), uma equipe de pesquisa deve ser selecionada para buscar o entrosamento. Desde o início do processo de convocação e de seleção dos alunos de iniciação cientifica, há uma etapa que é pedagógica, desse modo, é preciso esclarecer o que é tal atividade. De acordo, ainda, com Zakon (1989), deve haver um mês de treinamento para avaliar se é desejo do aluno permanecer no projeto. Há, também, no começo, um receio dos iniciantes em questionar, comentar ou tecer observações. A iniciação científica é uma atividade de pesquisa de cunho didático, cujo objetivo final é o aprendizado do aluno. Ainda, segundo o autor, estudantes hesitam em realizar estágios por falta de informações a respeito da pesquisa básica e aplicada e os benefícios envolvidos.

Dentre os benefícios, destacamos que a produção científica contribuiu para o ingresso 
em mestrados e doutorados. Para Fava-de-Moraes e Fava (2000), os estudantes de IC que apresentam desempenhos satisfatórios em processos de seleção para a pósgraduação, apresentam, também, mais facilidade no trabalho em equipe e em falar em público. Segundo Pinho (2017), a pesquisa pode contribuir para a autonomia, a criatividade, a construção de um raciocínio crítico do estudante e ampliar o conhecimento de uma área de atuação.

Nesse sentido, vemos como benéfica a implementação da pesquisa desde o período de graduação, por meio da iniciação científica, para que o estudante tenha a oportunidade de adquirir experiências significativas para sua vivência profissional e esteja mais preparado para prosseguir futuramente nos estudos de pós-graduação.

Autores, como Pinho (2017) e Pereira (2009), apontam para o fato de que as universidades ainda focam somente no ensino, há falta de investimentos e uma necessidade de maior engajamento por parte dos professores. Contrapondo essa situação, Massi (2015), em sua pesquisa de mestrado, diagnosticou que estudantes de IC evidenciam ter se apropriado de uma linguagem científica.

De acordo com o portal do CNPq (BRASIL, 2018):

É preciso que desde os primeiros anos da educação formal os(as) estudantes sejam postos em contato com a cultura científica, ou seja, com a maneira científica de produzir conhecimento e com as principais atividades humanas que têm moldado o meio ambiente e a vida humana ao longo da história.

No portal da Kroton (UNOPAR, 2018), são apresentados os benefícios de ser um aluno de IC no que diz respeito:

I) Aos trabalhos publicados em eventos científicos; II) Domínio da metodologia científica; III) Preparação para os programas de pós-graduação; IV) Valorização do currículo profissional; V) Desenvolvimento do pensar e do criar cientificamente; VI) Aprimoramento do espírito crítico e da criatividade e certificação de participação na Iniciação Científica.

Os estudantes podem participar, anualmente, do Seminário de Iniciação Científica, que tem como objetivo principal proporcionar aos bolsistas e aos respectivos orientadores, a oportunidade de expor e de discutir o resultado de suas pesquisas por meio da apresentação de trabalhos. 
O CNPq apresentou um relatório de avaliação do programa institucional de bolsas de iniciação científica, publicado em 2017, que contemplou 29 mil formulários on-line, respondidos por orientadores, incorporados a uma base de dados e disponibilizados pelo CNPq para essa análise. Nesse documento, quando são solicitados a avaliar as habilidades que a IC desenvolveu no bolsista, a avaliação também é positiva. Em pesquisas sobre os bolsistas da área de Ciências Exatas e da Terra, 39\% pretendiam continuar sua pesquisa na pós-graduação e outros 32\% vão para a pós-graduação.

\section{Descrição dos Procedimentos para a realização da Iniciação Científica na Educação a Distância}

Começamos o projeto com a preparação do edital de seleção dos estudantes para o projeto de IC e o convite para os professores colaboradores iniciarem, juntamente com o coordenador do projeto, a preparação dos materiais a serem disponibilizados e a orientação dos estudantes investigadores de campo. Contamos, para o desenvolvimento do projeto, com um Ambiente Virtual de Aprendizagem (AVA), no qual foram inseridas ferramentas de comunicação, como fórum e chat, já que a iniciação científica seria desenvolvida com estudantes de um curso EaD.

Foram inscritos doze alunos de cursos de licenciatura em Matemática. O projeto foi ofertado em polos de apoio, que têm cursos de licenciatura em Matemática e em Engenharia para atingir os objetivos propostos. A idade média é de vinte a trinta anos, sendo três do sexo masculino e nove do sexo feminino. Cada inscrito iniciou sua participação no projeto com a sua apresentação em fórum de discussão, apresentando suas expectativas. Desde o início, professores colaboradores realizaram a apresentação e receberam dos estudantes a recíproca. Foi disponibilizado um material explicativo sobre o projeto: um vídeo com os objetivos. Houve, também, uma simulação, por parte dos professores colaboradores, explicando, de forma lúdica e contextualizada, a necessidade de conhecimentos matemáticos para a formação do engenheiro.

Os alunos ingressantes na IC receberam um cronograma de atividades a serem desenvolvidas no período de 2017-2, após a seleção. A finalidade do cronograma foi auxiliar na organização das atividades a serem desenvolvidas para a conclusão da primeira etapa do projeto de iniciação científica.

Quadro 1: Atividades desenvolvidas em 2017-2 no projeto de IC.

\begin{tabular}{|l|l|l|}
\hline ATIVIDADES OBRIGATÓRIAS & PERÍODO & ACO \\
\hline Apresentar-se no fórum "Colocando a conversa em dia”. & $18 / 09$ a $18 / 11$ & 1 hora
\end{tabular}


Apresentar informações, tais como: que semestre está cursando, em que polo estuda, quais seus projetos e expectativas para depois da conclusão do curso (pretende cursar uma pósgraduação, lecionar, etc.) e mencionar suas expectativas com o PIC (que contribuições acredita que o PIC poderá proporcionar à sua formação?)

\begin{tabular}{|l|l}
\hline Fazer e postar, no ambiente virtual AVA, na pasta "Fichamento",05/10 a 08/12 & 16 horas
\end{tabular} os fichamentos dos textos.

Fazer somente 1 arquivo utilizando o Word (.doc ou .docx), seguindo as normas da ABNT. Ele deve conter no máximo 9 páginas.

guia para os fichamentos está no arquivo "Como fazer um fichamento" (já disponibilizado no nosso ambiente).

Verificar as normas da ABNT na Biblioteca Virtual, na página da Unopar.

Participar do chat mediado pelos docentes (escolher pelo menos $04 / 12$ a 08/12 (das 4 horas um dia no período informado).

Estudar as videoaulas já disponíveis no nosso ambiente.

Fazer um texto, no formato .doc ou .docx, colocando os pontos principais de cada tema analisado, seguindo as normas ABNT.

Fazer somente 1 arquivo com, no máximo, 6 páginas.

Postar no ambiente virtual AVA, na pasta "Texto - Síntese".

Criar e encaminhar o link do seu Currículo Lattes para o seuAté 15/12 orientador (por e-mail).

Do total das 8 questões matemáticas, que serão disponibilizadas $08 / 12 / 17$ pelos docentes do projeto no nosso ambiente AVA, selecionar as 19/02/18 4 que julgar mais importantes.

Postar no ambiente virtual AVA, no tópico do nosso fórum intitulado "Questões", as questões selecionadas por você, adicionando, a cada uma, os argumentos e os critérios que justifiquem suas escolhas. Para tanto, tenha como base as habilidades e competências estudadas nos textos fichados. 
Fonte: dos autores (2018).

O estudante contava com três canais para discutir as ideias relacionadas com as atividades propostas: o chat, o fórum e o contado via e-mail institucional com seu orientador. O chat foi aberto, semanalmente, para haver diálogo sobre a pesquisa, visando aos esclarecimentos.

A seguir, apresentamos exemplos da expectativa dos estudantes de IC individualizados por E1, E2, E3, E4. Estes textos foram postados no fórum do AVA, na atividade "Colocando a conversa em dia", na apresentação inicial do projeto:

E1: Acredito que o PIC vai e já está ampliando novos horizontes quando o assunto é conhecimento. As aulas são bem explicadas e os temas bem interessantes. Meu maior objetivo é contribuir nesse projeto e acima de tudo absorver o máximo de conhecimentos possíveis.

E2: O PIC deverá ser de grande valia para minha formação, acrescentando pontos importantes em meu currículo, além de um aperfeiçoamento profissional e pessoal.

E3: Minha expectativa em relação ao Projeto, é desenvolver muito conhecimento científicos e específicos, tendo sempre contato com a prática, ampliando sempre o conhecimento na área profissional, e ir em busca de novos objetivos, uma carreira acadêmica, estabelecendo sempre contato com professores e sempre que possível com pesquisadores qualificados.

E4: Para minha vida acadêmica e profissional o PIC é uma ferramenta quase que obrigatória na minha escadinha de escolaridade, onde pretendo passar por cada etapa possível até o pós-doutorado, tendo o gostinho de cada experiência que me prova além das teorias, que a Matemática não se aplica somente no ambiente escolar! Além de enriquecimento de currículo, também é reconhecimento para o meu polo de apoio, que não se limita somente à oferta e logo se dedica ao crescimento de seus alunos.

De acordo com os relatos apresentados, os estudantes esperam que o projeto traga conhecimento, compreendem que é uma atividade importante para o currículo profissional, visa à aproximação com pesquisadores experientes e entendem que é uma etapa importante para a pós-graduação.

A segunda atividade foi de fichamento de textos para estudo e discussão. Foram 
disponibilizados textos, para que os estudantes de iniciação científica: (i) compreendessem o que são competências e habilidades; (ii) compreendessem o papel da matemática para os profissionais de Engenharia; (iii) identificassem as competências e as habilidades que os egressos dos cursos de Engenharia devem ter, segundo as Diretrizes Curriculares; (iv) identificassem as competências e as habilidades a serem desenvolvidas na formação do engenheiro com relação à Matemática.

Para subsidiar os estudantes, foram fornecidas explicações orais sobre conceito de fichamento e sobre como elaborar esse tipo de texto. Foram disponibilizados links com outras referências de apoio e um vídeo, além de outras orientações sobre como o aluno deveria normatizar o fichamento. Apresentamos, a seguir, um exemplo de texto realizado pelo estudante $\mathrm{E} 5$ :

Quadro 2: Fichamentos do estudante E5, postado na plataforma AVA.

\section{Fichamento 1}

Tipo: Artigo

Assunto/Tema: Engenharia/ Matemática/ Cálculo Diferencial e Integral

Referência Bibliográfica Completa:

ALMEIDA, Maria E. B., FIDALGO, Carla I. F. O Ensino da Matemática nas Licenciaturas de Engenharia: ACAM-Avaliação de Competências/Ações de Melhoria. 2013. Disponível em:< https://www.researchgate.net/publication/260857450_O_ensino_da_Matematica_nas licenciaturas de Engenharia_ACAMAvaliacao de competenciasacoes_de melhoria>. Acesso em: 18/11/2017.

Resumo:

O texto fala sobre as dificuldades que os alunos das licenciaturas em engenharias apresentam em relação ao Cálculo Diferencial e Integral no que se refere a alguns conteúdos básicos da Matemática, o que vem acarretando altas taxas de reprovação e abandono das aulas.

As autoras apresentam gráficos que demonstram a origem dos alunos ingressantes nos cursos superiores de engenharias, taxas de frequência às aulas, taxas de aprovação e um gráfico com as principais habilidades matemáticas apresentadas por alunos de diferentes cursos das engenharias.

Citações:

'No entanto, a importância da Matemática e o seu papel estruturante enquanto ciência de 
base e ferramenta de suporte a um raciocínio lógico e estruturado, indispensável às áreas da engenharia, tem propulsionado a tentação dos docentes aceitarem, como normal, aquela situação, sendo envidados esforços para melhor compreensão dos fatores que contribuem no sucesso." (p.04).

"Tal como em Portugal, na década de 90 começaram a surgir problemas na lecionação das disciplinas de matemática, em particular, nas licenciaturas em Engenharia. São inúmeras as publicações que salientam a falta de conhecimentos básicos e elementares ao nível da matemática, elevadas taxas de retenção e o aumento do número de alunos que fogem aos cursos que requerem conhecimentos de matemática." (p. 10).

Local:

Disponível em:<

https://www.researchgate.net/publication/260857450_O_ensino_da_Matematica_naslicenciat uras de_Engenharia_ACAMAvaliacao_de_competenciasacoes_de melhoria>. Acesso em $18 / 11 / 2017$.

\section{Fichamento 2}

Tipo: Texto PDF

Assunto/Tema: Competências matemáticas nos cursos de Engenharias.

Referência Bibliográfica Completa:

BIANCHINI, Barbara L.; LIMA, Gabriel L.; GOMES, Eloíza; NOMURA, Joelma I. Competências Matemáticas: Perspectivas da SEFI e da MCC. 2017. Disponível em: https://revistas.pucsp.br/index.php/emp/article/view/30194>. Acesso em: 18/11/2017.

Resumo:

Os autores, docentes de cursos de engenharias, fizeram um minucioso estudo sobre as competências matemáticas no trabalho de engenheiros através dos estudos de diversos autores nacionais e internacionais. Apresentam as convergências entre as ideias difundidas pela MCC e por Alpers et al. (2013) a respeito das competências matemáticas importantes para que os alunos das engenharias tenham uma formação satisfatória.

O artigo faz considerações sobre o tema "competências", a origem do termo e sua contribuição na educação. Traz também o conceito de competência para diversos autores e a concepção de competências para alguns países.

Texto de fácil leitura e com diversas citações de renomados autores.

Citações:

"A contextualização da Matemática no ensino de Engenharia tem implicação direta na 
motivação do aluno em estudar os conceitos desta ciência." (p.54).

"De maneira mais evidente em alguns momentos e menos em outros, a noção de competência e/ou a ideia de educação por competências passou a permear os diferentes níveis educacionais." (p. 61).

"Fica evidente, então, a necessidade de participação ativa dos estudantes dos cursos de Engenharia em suas formações de forma a possibilitá-los o desenvolvimento da capacidade de usar a Matemática em contextos reais." (p. 62).

"Conforme descrevem Alpers et al. (2013), as competências matemáticas desenvolvidas pelos futuros engenheiros estão diretamente relacionadas às atividades vivenciadas pelos estudantes durante seu curso de graduação, uma vez que o desenvolvimento de determinada atividade requer o exercício de uma ou várias competências matemáticas." ( $p$. $67)$.

"Ou seja, para Camarena, as aulas de Matemática em um curso de engenharia, além de oportunizarem o desenvolvimento de competências matemáticas, podem também proporcionar a construção de competências laborais e profissionais." (p.74).

Local: Texto disponível em:< https://revistas.pucsp.br/index.php/emp/article/view/30194>. Acesso em: 18/11/2017.

Fonte: dos autores (2018).

\section{Considerações finais}

Ressaltamos que o projeto continua em andamento e, neste texto, apresentamos apenas as suas atividades iniciais e a percepção de alguns dos estudantes inscritos na IC. Diante do empenho do grupo, observado por meio do acompanhamento do chat, nos fóruns das disciplinas, postagens das atividades solicitadas e nas reuniões semanais, realizadas pelos professores colaboradores e a coordenação do projeto, temos como resultado desse trabalho, que os estudantes inscritos compreendem a necessidade de realizar a pesquisa desde o início da formação, para ter a oportunidade de desenvolver atividades de cunho científico, favorecendo seu desenvolvimento profissional e educacional.

Nesse sentido, compreendemos que as IES devem favorecer as atividades e as práticas de iniciação científica, visando atender as expectativas dos estudantes, pois, nesse tipo de pesquisa, promovemos uma grande diversidade de trocas de experiência e 
melhoramos a formação para os graduandos, para os docentes e para os demais envolvidos no processo.

\section{Bibliografia}

BRASIL. CNPQ. Iniciação Científica. Disponível em: <http://cnpq.br/iniciacao-cientifica>. Acesso em: 24 abr. 2018.

CENTRO DE GESTÃO E ESTUDOS ESTRATÉGICOS. A Formação de novos quadros para CT\&I: avaliação do programa institucional de bolsas de iniciação. Brasília: CGEE, 2017. Disponível em: <https://goo.gl/xAyPas>. Acesso em: 24 abr. 2018.

FAVA-DE-MORAES, Flávio; FAVA, Marcelo. A iniciação científica: muitas vantagens e poucos riscos. São Paulo Perspec., São Paulo , v. 14, n. 1, p. 73-77, mar. 2000. Disponível em:< https://goo.gl/fkRIOP>. Acesso em: 24 abr. 2018.

PINHO, Maria José de. Ciência e ensino: contribuições da iniciação científica na educação superior. Avaliação (Campinas) [online], 2017, v. 22, n.3, p.658-675. Disponível em: <http://dx.doi.org/10.1590/s1414-40772017000300005>. Acesso em: 24 abr. 2018.

UNOPAR. A iniciação científica. Disponível em: <https://goo.gl/Xeodg3 >. Acesso em: 24 abr. 2018.

ZAKON, A. Qualidades desejáveis na iniciação científica. Ciência e Cultura, v. 41, n. 9, p. 868-877, 1989. 